Key Words:

Mixing, MST,

SCIX

Retention:

Permanent

\title{
Investigating Suspension of MST Slurries in a Pilot-Scale Waste Tank
}

Michael R. Poirier

Zafar H. Qureshi

Michael L. Restivo

Timothy J. Steeper

Michael R. Williams

January 24, 2011

Savannah River National Laboratory Savannah River Nuclear Solutions Aiken, SC 29808 


\section{DISCLAIMER}

This work was prepared under an agreement with and funded by the U.S. Government. Neither the U. S. Government or its employees, nor any of its contractors, subcontractors or their employees, makes any express or implied:

1. warranty or assumes any legal liability for the accuracy, completeness, or for the use or results of such use of any information, product, or process disclosed; or

2. representation that such use or results of such use would not infringe privately owned rights; or

3. endorsement or recommendation of any specifically identified commercial product, process, or service.

Any views and opinions of authors expressed in this work do not necessarily state or reflect those of the United States Government, or its contractors, or subcontractors.

Printed in the United States of America

Prepared for

U.S. Department of Energy 
Key Words:

Mixing, MST,

SCIX

Retention:

Permanent

\title{
Investigating Suspension of MST Slurries in a Pilot-Scale Waste Tank
}

\author{
Michael R. Poirier \\ Zafar H. Qureshi \\ Michael L. Restivo \\ Timothy J. Steeper \\ Michael R. Williams
}

January 24, 2011

Savannah River National Laboratory

Savannah River Nuclear Solutions

Savannah River Site

Aiken. SC 29808 


\section{REVIEWS AND APPROVALS}

AUTHORS:

M. R. Poirier, SRNL, Advanced Characterization \& Processing

Date

Z. H. Qureshi, SRNL, Engineering Development Laboratory

Date

DESIGN CHECK:

K. Adu-Wusu, SRNL, Advanced Characterization \& Processing

Date

APPROVAL:

F. M. Pennebaker, Manager

Date

Advanced Characterization \& Processing

S.L. Marra, Manager

Date

Environmental \& Chemical Process Technology Research Programs

CUSTOMER:

T. H. Huff, SRR, Small Column Ion Exchange Project Design Authority Date 


\section{TABLE OF CONTENTS}

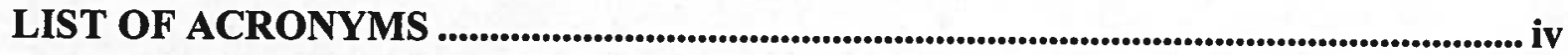

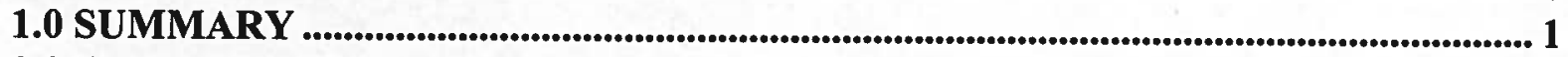

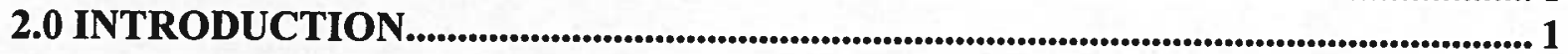

3.0 TEST EQUIPMENT AND TESTING DESCRIPTION ....................................................... 2

3.1 PILOT SCALE TEST FACILITY DESCRIPTION........................................................ 2

3.2 EXPERIMENTAL STEPS ....................................................................................................... 7

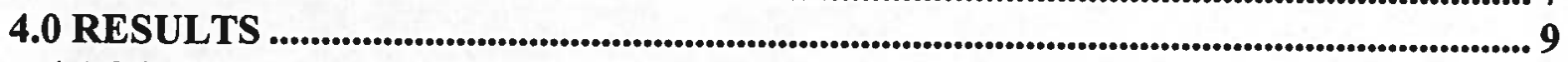

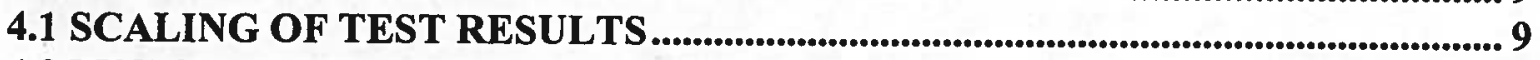

4.2 MST SUSPENSION TESTS WITH TWO PUMPS ......................................................... 9

4.3 MST RESUSPENSION TEST WITH TWO PUMPS..................................................... 12

4.4 MST SUSPENSION TEST WITH THREE PUMPS ...................................................... 13

4.5 MST RESUSPENSION TEST WITH THREE PUMPS …....................................... 14

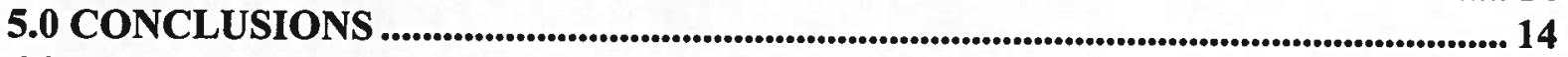

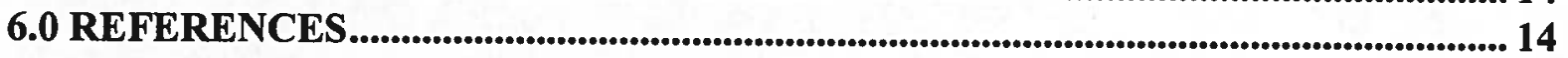




\section{LIST OF ACRONYMS}

$\begin{array}{ll}\text { ARP } & \text { Actinide Removal Process } \\ \text { CST } & \text { Crystalline Silicotitanate } \\ \text { DWPF } & \text { Defense Waste Processing Facility } \\ \text { EDL } & \text { Engineering Development Laboratory } \\ \text { MST } & \text { Monosodium Titanate } \\ \text { P\&ID } & \text { Process and Instrument Diagram } \\ \text { RMF } & \text { Rotary Microfilter } \\ \text { rpm } & \text { revolutions per minute } \\ \text { SCLX } & \text { Small Column Ion Exchange } \\ \text { SMP } & \text { Submersible Mixer Pumps } \\ \text { SRNL } & \text { Savannah River National Laboratory } \\ \text { SRR } & \text { Savannah River Remediation } \\ \text { SRS } & \text { Savannah River Site } \\ \text { VFD } & \text { Variable Frequency Drive }\end{array}$




\subsection{SUMMARY}

The Small Column Ion Exchange (SCIX) process is being developed to remove cesium, strontium, and actinides from Savannah River Site (SRS) Liquid Waste using an existing waste tank (i.e., Tank $41 \mathrm{H}$ ) to house the process. Savannah River National Laboratory (SRNL) is conducting pilot-scale mixing tests to determine the pump requirements for suspending monosodium titanate (MST), crystalline silicotitanate (CST), and simulated sludge. The purpose of this pilot scale testing is for the pumps to suspend the MST particles so that MST can be removed from the tank.

The pilot-scale tank is a $1 / 10.85$ linear scaled model of Tank $41 \mathrm{H}$. The tank diameter, tank liquid level, pump nozzle diameter, pump elevation, and cooling coil diameter are all 1/10.85 of their dimensions in Tank $41 \mathrm{H}$. The pump locations correspond to the proposed locations in Tank $41 \mathrm{H}$ by the SCIX program (Risers B5 and B2 for two pump configurations and Risers B5, $\mathrm{B} 3$, and B1 for three pump configurations).

The conclusions from this analysis follow.

- Neither two standard slurry pumps nor two quad volute slurry pumps will provide sufficient power to initially suspend MST in an SRS waste tank.

- Two Submersible Mixer Pumps (SMPs) will provide sufficient power to initially suspend MST in an SRS waste tank. However, the testing shows the required pump discharge velocity is close to the maximum discharge velocity of the pump (within 12\%).

- Two SMPs will not provide sufficient power to resuspend MST that has settled in a waste tank at nominal $45^{\circ} \mathrm{C}$ for four weeks.

- Three SMPs will provide sufficient power to initially suspend MST in an SRS waste tank. The testing shows the required pump discharge velocity is $66 \%$ of the maximum discharge velocity of the pump.

- Three SMPs will provide sufficient power to resuspend MST that has settled in a waste tank at nominal $45^{\circ} \mathrm{C}$ for four weeks. The testing shows the required pump discharge velocity is $77 \%$ of the maximum discharge velocity of the pump.

\subsection{INTRODUCTION}

Savannah River Remediation (SRR) is developing the SCIX process to remove cesium, strontium, and select actinides from SRS Liquid Waste using an existing waste tank (i.e., Tank $41 \mathrm{H}$ ) to house the process. The process adds MST as a slurry to the waste tank (i.e., Tank $41 \mathrm{H}$ ) to chemically sorb the strontium and select actinides, removes the MST and entrained sludge with an in-riser rotary microfilter (RMF), and removes cesium from the RMF filtrate with ion-exchange columns containing CST. The RMF returns the concentrated solids (i.e., MST and entrained sludge) to the waste tank. After being loaded with cesium, the CST is ground to reduce its size and transferred as slurry to Tank $40 \mathrm{H}$ (baseline case) or Tank $41 \mathrm{H}$. The MST, sludge, and CST (if transferred to Tank $41 \mathrm{H}$ ) in the waste tank will be periodically transported to a sludge batch preparation tank (Tank 42H or Tank 51H). Both the MST and CST streams will ultimately be transferred to the Defense Waste Processing Facility (DWPF) for vitrification. 
To assist SRR in designing the SCIX process, SRNL is conducting pilot-scale testing to determine the number, type, and size of pumps needed to suspend/resuspend the solid particles (i.e., MST, CST, and sludge) in Tank $41 \mathrm{H}^{1}$

The purpose of this mixing application is for the MST to adequately contact the strontium and actinide containing liquid and to remobilize the solid particles so they can be removed from the tank. There are no requirements for the MST to be homogeneous in the tank during either mixing activity.

The objectives of the pilot-scale testing follow:

- To determine the strontium sorption by MST as a function of time [These test results will be described in a technical report to be issued later]

- To determine the pump requirements (i.e., number, size, and speed) to suspend solids for adequate contact with salt solution and resuspend settled solids after sitting in the tank for an extended period of time.

This document describes the tests conducted to determine the pump requirements to suspend MST in Tank $41 \mathrm{H}$ with and without settling for four weeks at nominal $45^{\circ} \mathrm{C} .{ }^{\mathrm{a}}$ Additional tests will be performed to determine the pump requirements to resuspend MST plus CST slurries and MST plus CST plus simulated sludge slurries that have settled for four weeks at nominal $45^{\circ} \mathrm{C}$. Those test results will be documented at a later date in a separate report. The strontium sorption test results will be described in a future report, as well.

\subsection{TEST EQUIPMENT AND TESTING DESCRIPTION}

\subsection{PILOT SCALE TEST FACILITY DESCRIPTION}

To meet the above objectives, a 1/10.85 scale facility was designed, fabricated, and assembled in the Engineering Development Laboratory (EDL) of SRNL. The main tank is a nominal 8 foot diameter, 41 inch high transparent acrylic tank of wall thickness 1 inch. The pilot-scale tank contains cooling coils, which were fabricated from $1 / 4$ inch stainless steel tubing $(0.25$ inch OD) and linearly scaled to the diameter of the cooling coils in Tank $41 \mathrm{H}$. The coils were arranged to replicate the cooling coils in Tank $41 \mathrm{H}$ and glued to an acrylic plate prior to placing them in the pilot-scale tank. A photograph of the clear tank with scaled Tank $41 \mathrm{H}$ cooling coils is shown in Figure 1. The acrylic tank sits on a 38 inch high open steel stand. This design facilitated direct visual observation of the cleaning radius from underneath since the tank bottom is transparent. At the center of the tank, a stainless steel center column is provided.

One of the key design requirements was to provide a means to keep the tank contents heated up to $45^{\circ} \mathrm{C}$ for prolonged periods while the tank contents are settling. SRNL designed the heating system without compromising the ability to directly visualize solid suspension through the tank bottom. This feature was accomplished by providing a false bottom inside the acrylic tank. The cooling coil assemblies are attached to two half circle $1 / 2$ inch thick acrylic plates. The two plates

\footnotetext{
${ }^{\mathrm{a}}$ Temperature $=43 \pm 3^{\circ} \mathrm{C}$
} 
were connected together before lowering the coil assembly into the tank. The coil assembly plate is supported by a 1.25 inch outer diameter hard plastic pipe placed around the inside circumference of the tank. This arrangement yields a 1.25 inch gap between the coil assembly plate and the tank bottom. This gap serves as the heating jacket to keep the tank contents at the desired temperature. The 1.25 inch false bottom has supply and return lines through the tank center column to recirculate the heating fluid within the false bottom. Tank supernate fluid is used as the false bottom heating fluid. The use of this heating fluid precludes any change in tank contents from leakage between the tank and the false bottom. A custom molded insert was installed at the tank bottom corner to ensure the tank bottom corner is rounded to a $1 / 10.85$ scale of the Tank $41 \mathrm{H}$ bottom. This addition to the tank was included to eliminate sharp corners, which could have caused atypical accumulation of solids. With the clear coil assembly plate and the tank bottom, a direct observation and quantitative measurements of cleaning radii under different pumping conditions are possible.

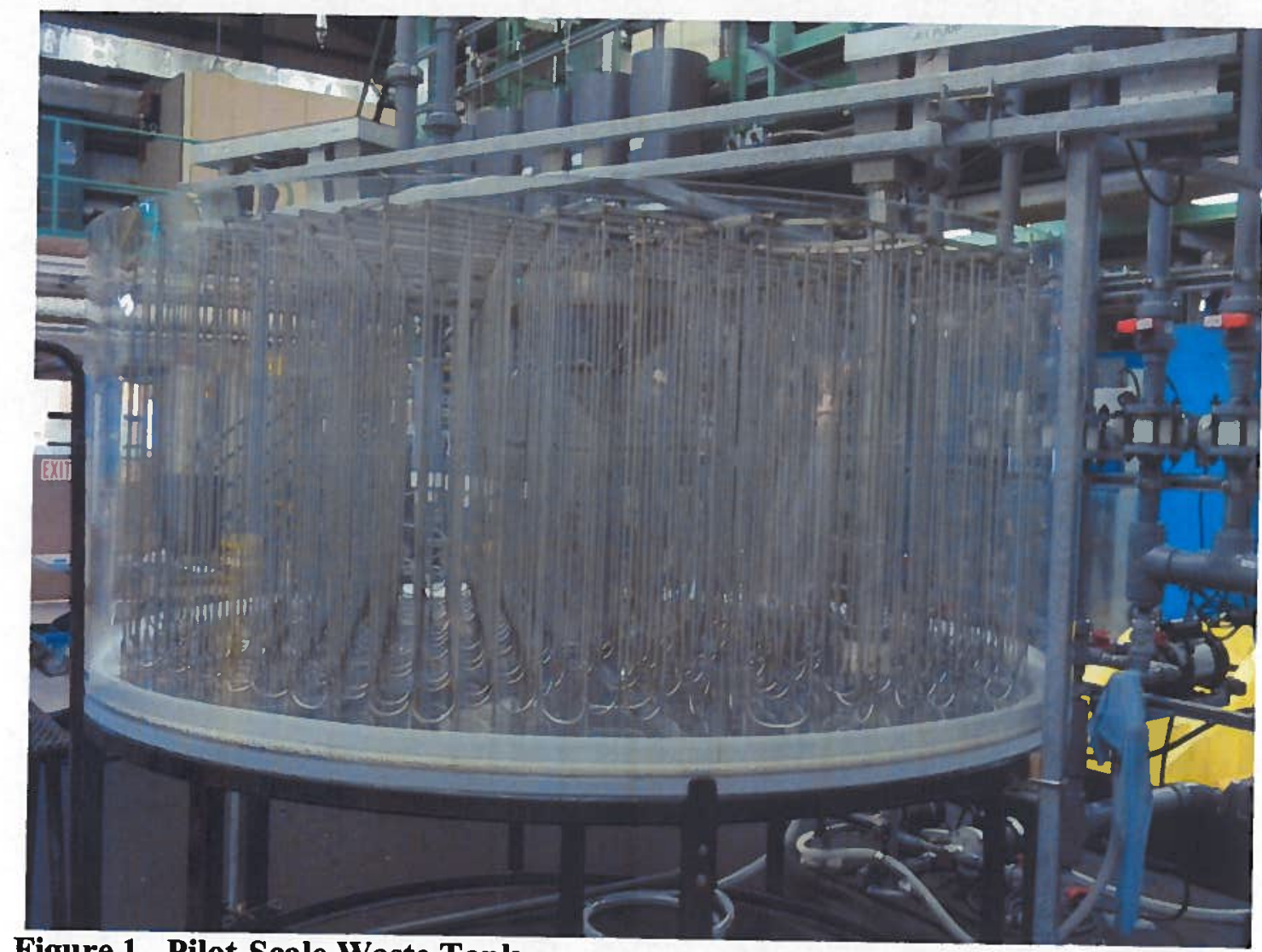

Figure 1. Pilot-Scale Waste Tank

Figure 2 shows a top view of the pilot-scale tank with the riser locations corresponding to Tank $41 \mathrm{H}$. The black and green line segments show the cooling coils. Researchers originally designed and built two rotating mixer pumps, which were placed in Risers B5 and B2. Based on the initial results ${ }^{b}$, SRR and SRNL increased the number of pumps to three. These pumps were placed in Risers B5, B3, and B1. Details of the mixer pump are provided later in this section.

\footnotetext{
b In the resuspension test with two SMPs, the pumps were not able to resuspend all of the MST that settled for four
weeks at $45^{\circ} \mathrm{C}$.
} 
The maximum cleaning radius needed to completely suspend the MST with three pumps is 47.1 inches $(42.6$ feet in Tank $41 \mathrm{H})$ in the pilot-scale tank. The liquid volume is 800 gallons, which is geometrically-scaled to the expected volume in Tank $41 \mathrm{H}\left[1,000,000\right.$ gallons $\left./(10.85)^{3}\right)$ $=780$ gallons $\sim 800$ gallons]. The pumps have interchangeable discharge nozzles to simulate standard slurry pumps, quad volute slurry pumps, and SMPs. The nozzle diameters are linearly scaled to the actual pumps. Figure 3 shows the dimensions of the pilot-scale SMP.

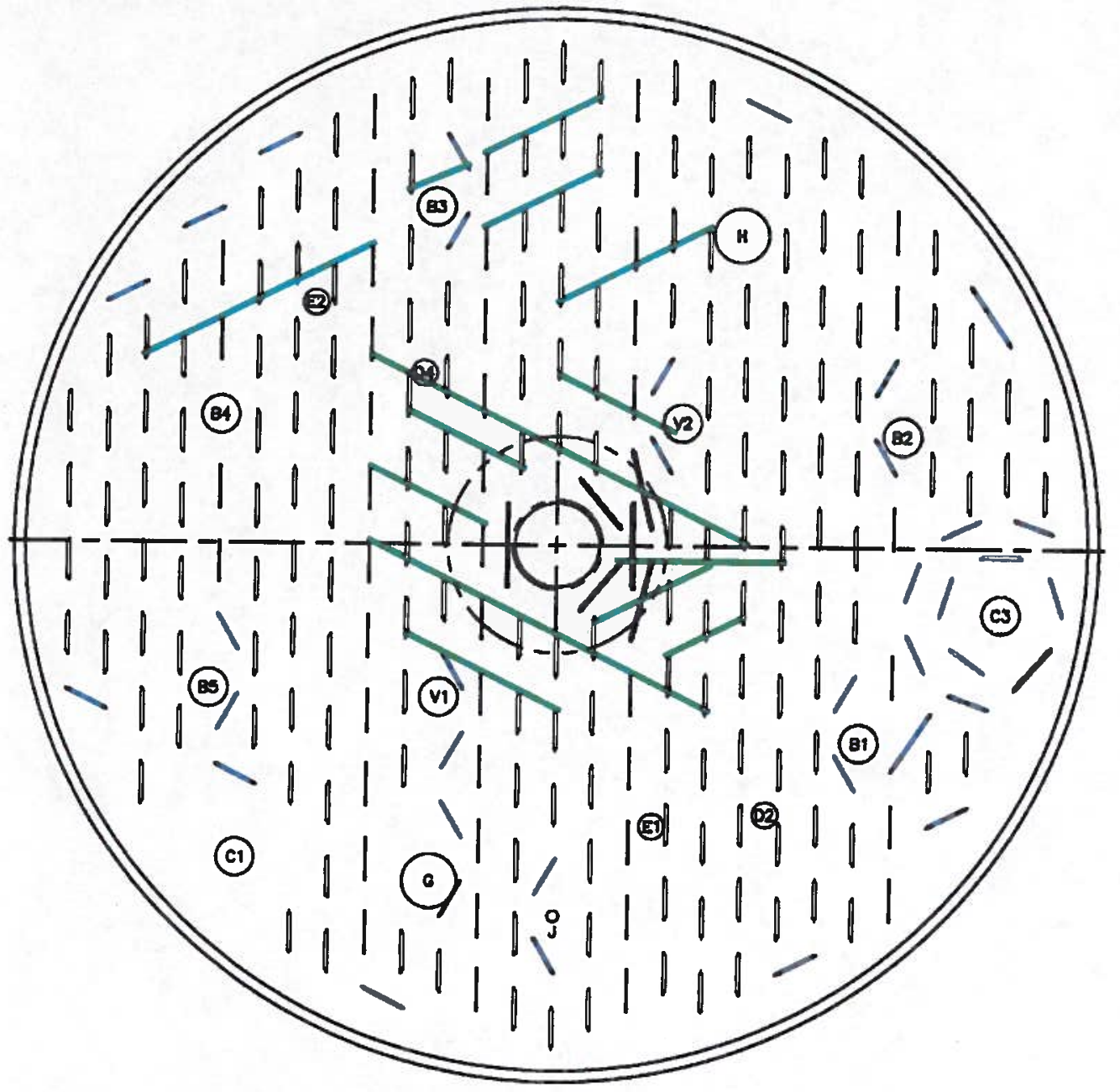

Figure 2. Pilot-Scale Tank Top View 


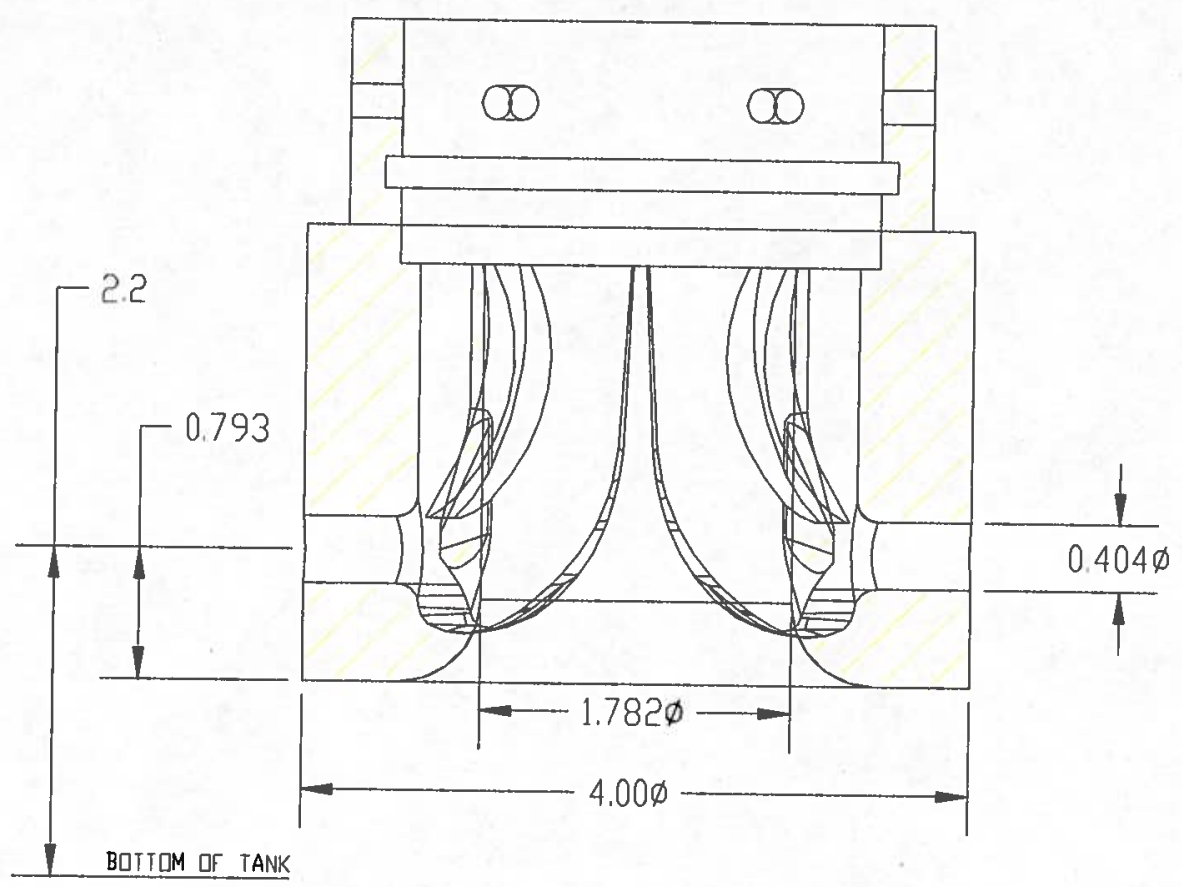

\section{Figure 3. Pilot-Scale SMP Head ${ }^{c}$}

Figure 4 shows details of the mixer pump assembly. The Tank $41 \mathrm{H}$ pumps have their drive motors located on top of the tank. Liquid enters through a bottom opening and is discharged through two nozzles placed 180 degrees apart. SRNL designed the pumps to preserve these characteristics in the pilot scale facility. The system uses an external pump to achieve the desired flow field. The pilot-scale mixer pump was designed to accommodate different pump heads at the bottom. Three sets of pump heads (SMP, quad volute, and standard pump) were designed and fabricated by a rapid prototyping method. Details of an SMP head are shown above in Figure 3. Using an external pump has two advantages - a) an accurate measurement of flow and b) simplicity of the pump head design.

Pump heads were fabricated from acrylic, polycarbonate, and ABS/polycarbonate. During fabrication, we attempted to replicate the internal flow passages of the standard, quad volute and submersible mixer pumps deployed in the SRS Tank Farm. Because of the complexity of the flow paths, the pilot-scale pump heads were not amenable to standard machine practices. Therefore, SRNL employed the rapid prototype method to fabricate the pump heads. Following the fabrication of the pilot-scale pump heads by the rapid prototype method, key pump head dimensions were machined to reduce their variance from the target dimensions. The pump heads were inspected before, during, and after use.

\footnotetext{
${ }^{\mathrm{c}}$ Dimensions are in inches.
} 


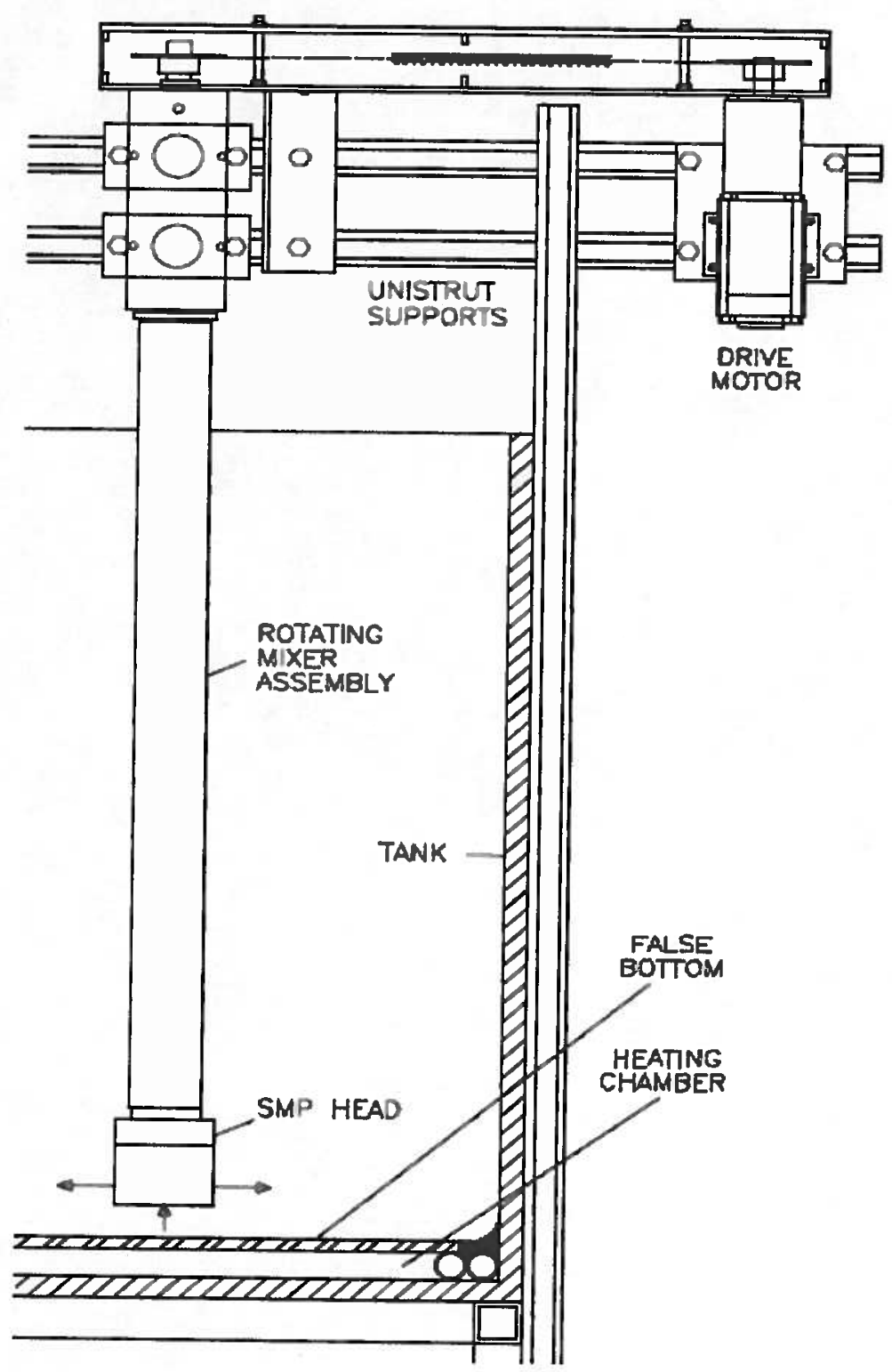

\section{Figure 4. Mixer Pump Details}

As shown in Figure 4, the fluid enters through the bottom of the pump head and after going through external pumping and flow measurements, it is discharged through the two nozzles 180 degrees apart. The fluid coming out the nozzles is parallel to the tank bottom as in Tank $41 \mathrm{H}$. The flow rate to each mixer pump is proportional to the jet velocity at the discharge point. The discharge velocity is the most important parameter for resuspension of solids in the tank. It can be calculated using Equation (1) below

$$
\mathrm{U}_{0}=4 \mathrm{Q} / \pi \mathrm{D}^{2}
$$

where $\mathrm{U}_{0}$ is the average pump nozzle discharge velocity, $\mathrm{Q}$ is the flow rate through the pump nozzle, and $\mathrm{D}$ is the nozzle diameter. Additionally, the mixer pumps are designed to rotate the 
pump heads. For the present tests, all mixing pump heads were rotated at 3.6 revolutions per minute (rpm) (for basis, see section 4.1). The nozzle orientation for different heads was not synchronized. Instead, it was kept at a random orientation to mimic prototypic conditions.

Figure 5 illustrates the process and instrumentation diagram (P\&ID) for the Pilot-Scale Test Facility. It schematically shows the mixing tank, three mixer pumps, external pump for mixers and instrumentation to measure flow rates, and process temperatures. The tank heating system is also shown. The heating fluid in the false bottom is circulated independently by a separate pump through a 6700 watt heater. The fluid temperature at the heater outlet is measured to control the heater which turns on or off as needed. For the settling and resuspension tests, the temperature was controlled to $43 \pm 3^{\circ} \mathrm{C}$. The main circulation pump is controlled by a variable frequency drive (VFD) controller. This controller varies the main pump motor speed to achieve different flow rates through the mixer pumps. Additional flow balancing in the mixer pump is achieved by throttling a valve in each flow path.

Two additional vane type pumps are also provided for chemical transfers in and out of the tank. These vane pumps are also used to prime the centrifugal pump and vent the air out of the flow loop.

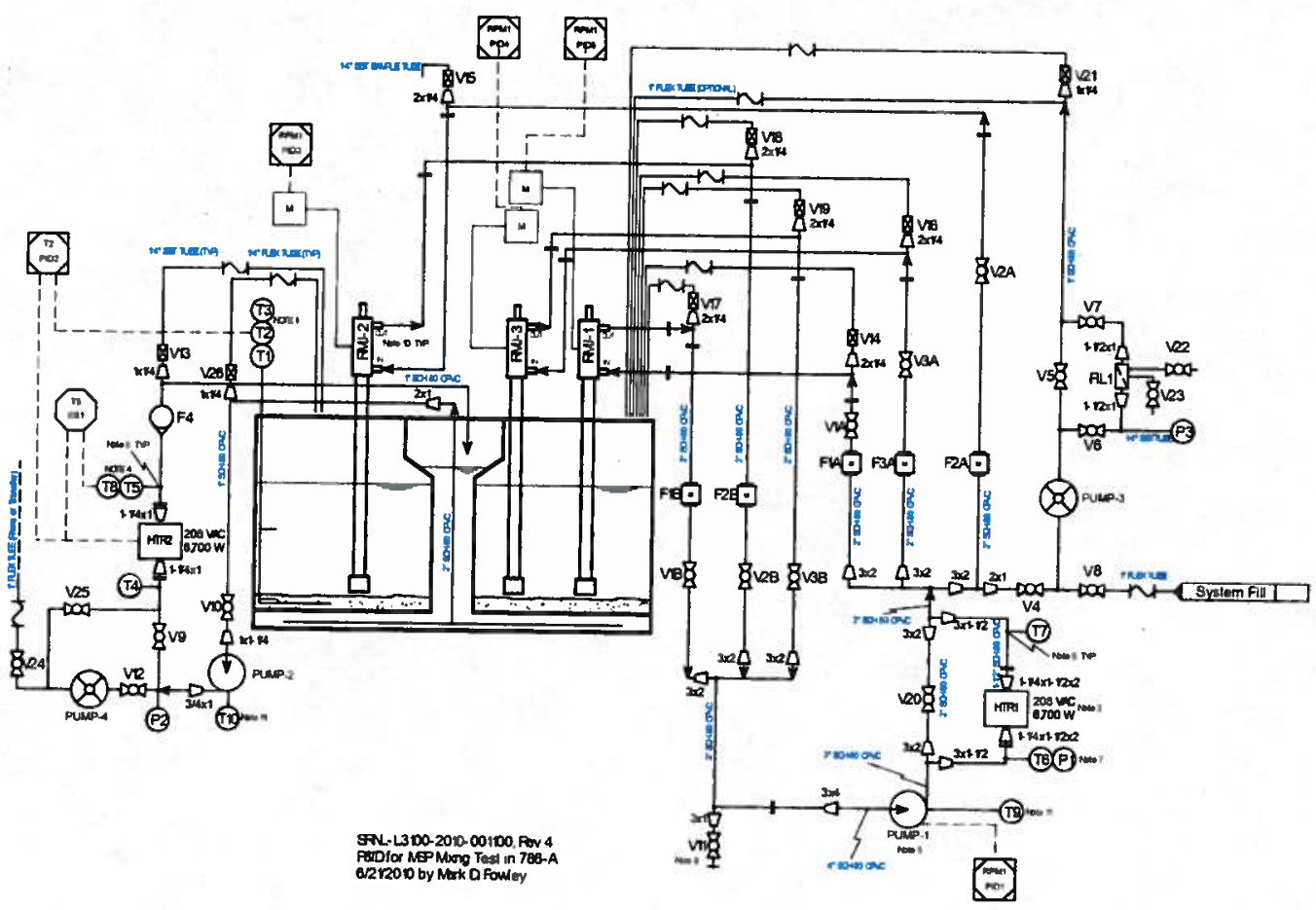

Figure 5. Process and Instrumentation Diagram of Pilot Scale Test Facility

\subsection{EXPERIMENTAL STEPS}

MST initial suspension tests were performed in the following manner. The feed tank was filled with 800 gallons of simulated supernate solution from Table 1 by measuring liquid to the premeasured mark in the tank. To this solution, 10 gallons of $15 \mathrm{wt} \%$ MST slurry was added. This amount was selected to be equivalent to approximately 5 MST strikes and to provide a layer 
of settled MST approximately $1 / 2$ inch thick. The MST was allowed to settle overnight at ambient temperature.

Table 1. Simulated Supernate Solution Recipe

\begin{tabular}{|c|c|}
\hline Ionic Species & Tank 37F, Molar \\
\hline $\mathrm{Na}^{+}$ & 6.44 \\
\hline $\mathrm{NO}_{3}^{-}$ & 2.26 \\
\hline $\mathrm{NO}_{2}^{-}$ & 0.74 \\
\hline $\mathrm{OH}^{-}$ & 2.57 \\
\hline $\mathrm{AlO}_{2}^{-}$ & 0.35 \\
\hline $\mathrm{CO}_{3}^{-2}$ & 0.11 \\
\hline $\mathrm{SO}_{4}^{-2}$ & 0.15 \\
\hline $\mathrm{SiO}_{3}^{-2}$ & $0.004^{\mathrm{d}}$ \\
\hline
\end{tabular}

Following the settling, the mixer pumps were operated at increasing flow rates and the cleaning radius was measured along each of three radial lines extending from each pump (see Figure 6). The recorded cleaning radius was the minimum of the measured values that were less than the distance to the wall or center column. The pump flow rate was increased until all MST particles were suspended or the maximum pump flow rate was reached. Individual MST suspension tests were performed with standard pump heads, quad volute pump heads, and SMP pump heads.
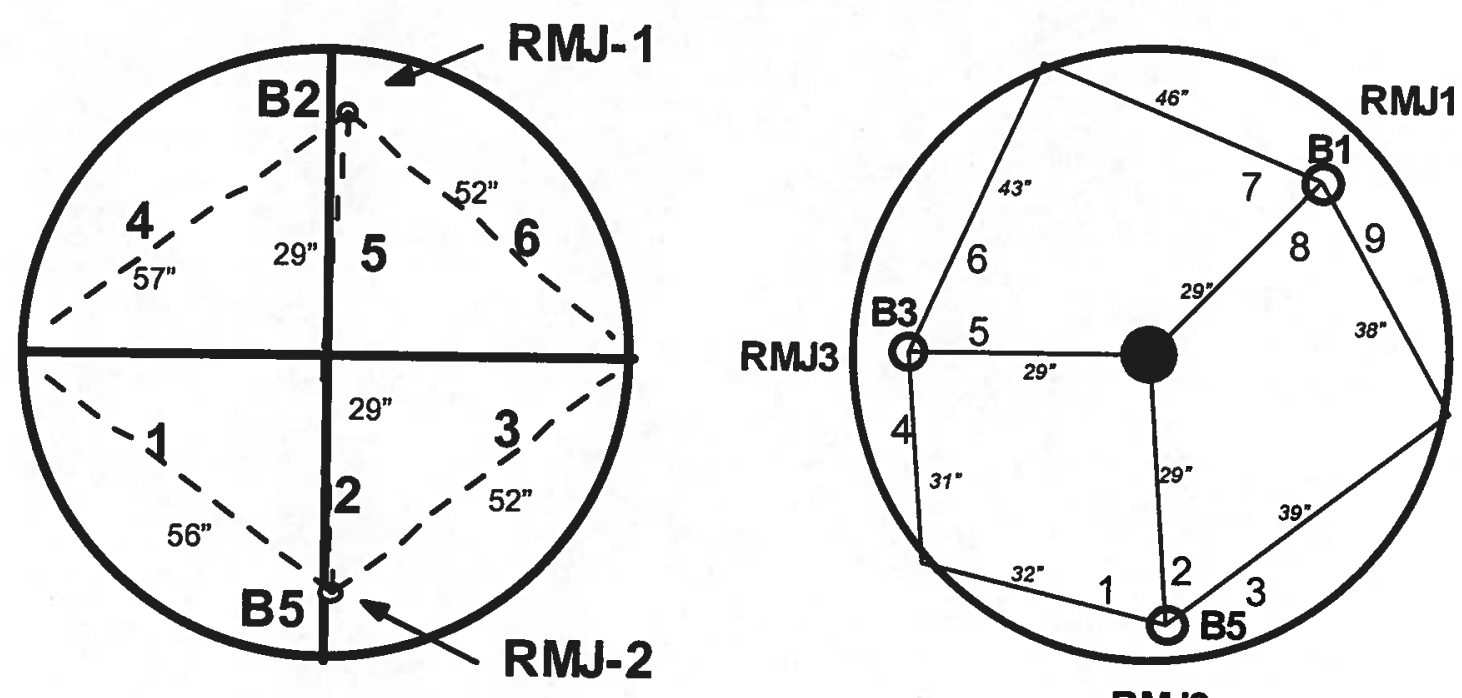

RMJ2

Figure 6. Cleaning Radius Measurement Locations for Two and Three Pump Configuration

For the resuspension tests, the MST was allowed to settle for four weeks at nominal $45^{\circ} \mathrm{C}$. Following the settling, the mixer pumps were operated at increasing flow rates and the cleaning radius was measured at each flow rate. Researchers measured the cleaning radius along each of

${ }^{\mathrm{d}}$ Based on SRS average salt solution 
three radial lines extending from each pump (see Figure 6). The recorded cleaning radius was the minimum of the measured values that were less than the distance to the wall or center column. The flow rate was increased until all MST particles were suspended or the maximum pump flow rate was reached.

The resuspension tests were performed with SMP pump heads only based on the results of the MST suspension tests.

\subsection{RESULTS}

\subsection{SCALING OF TEST RESULTS}

The pilot-scale results must be applied to the full-scale waste tanks. The scaling of test results from pilot-scale to full-scale is described in another SRNL document. ${ }^{2}$ In that document, a conservative estimate of the scaling function was developed below.

$$
\mathrm{U}_{0 \text {-full-scale }}=1.3 \mathrm{U}_{0 \text {-pilot-scale }}
$$

where $\mathrm{U}_{0}$ is the nozzle discharge velocity. The nozzle discharge velocity in the full-scale tank is $30 \%$ larger than the nozzle discharge velocity in the pilot-scale tank for equivalent solid particle suspension. This scaling is conservatively based on matching the shear stress at the solid-liquid interface in both tanks. ${ }^{e}$ The cooling coils will cause less drag and less reduction in jet velocity in the full-scale tank compared with the pilot-scale tank. ${ }^{2}$ Therefore, the recommended pump nozzle velocity in the full-scale tank contains some conservatism.

The pump rotation rate in the pilot-scale tests should be 8.35 - 10.85 times the pump rotation rate in the full-scale tank. ${ }^{2}$ Since previous SRNL testing showed a slower rotation rate may provide improved solids suspension, SRNL increased the pump rotation rate 10.85 times rather than 8.35 times to be conservative. Given typical pump rotation rates in the SRS Tank Farms are 1/5-1/3 $\mathrm{rpm}$, the pump rotation rate in these tests was $3.6 \mathrm{rpm}(0.33 \mathrm{rpm} * 10.85=3.6 \mathrm{rpm})$.

\subsection{MST SUSPENSION TESTS WITH TWO PUMPS}

MST suspension tests were conducted with each type of pump using the two pump configuration described earlier. Figure 7 shows a typical plot of cleaning radius as a function of $\mathrm{U}_{0} \mathrm{D}$, which is calculated through equation (1). The cleaning radius along each line increases approximately linearly, until the center column or tank wall is reached.

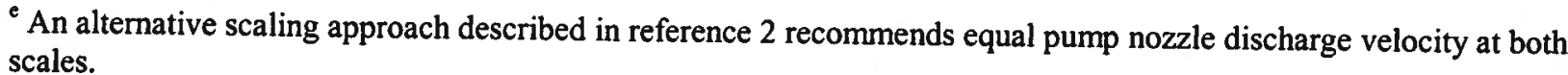




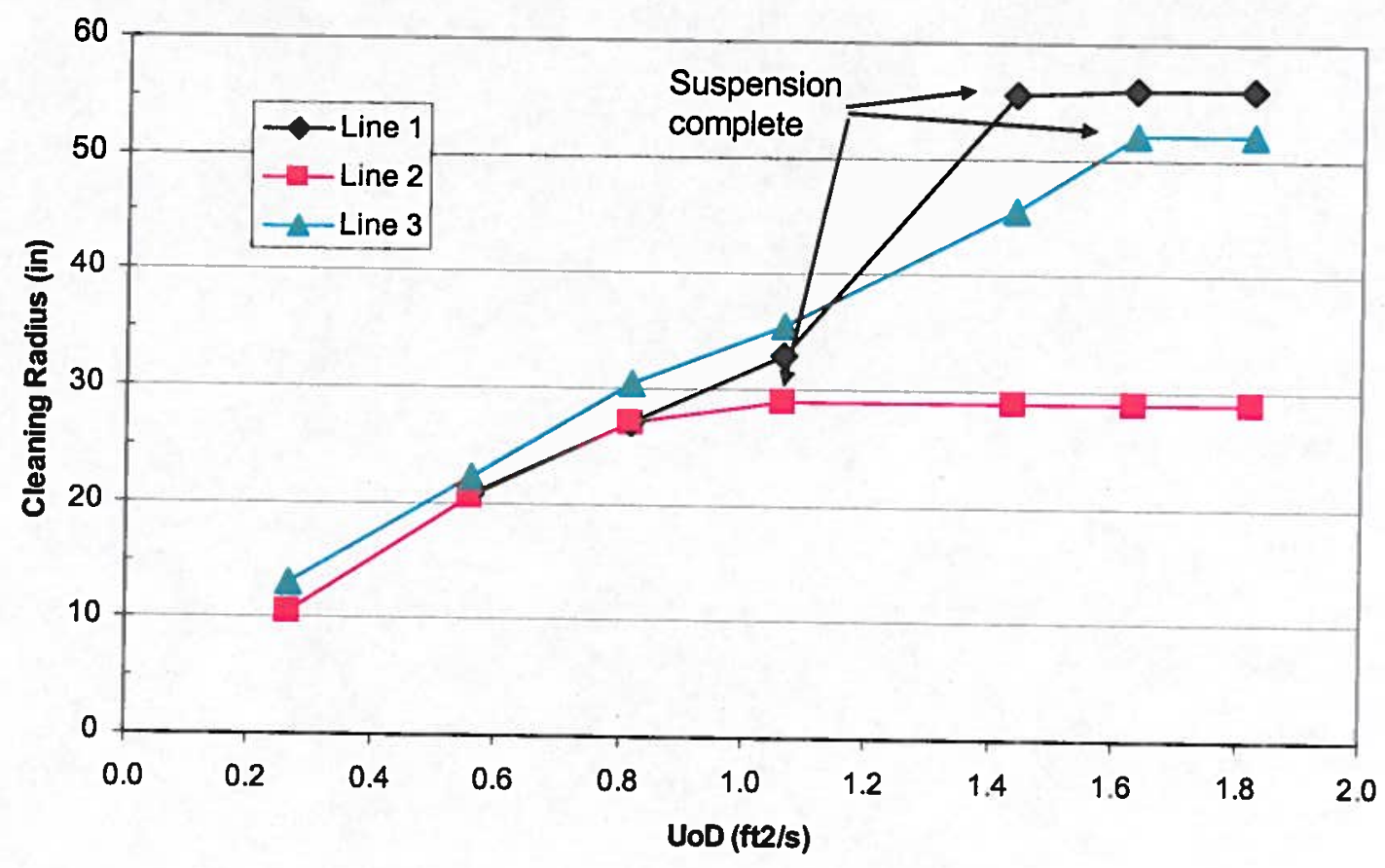

\section{Figure 7. Cleaning Radius as a Function of $\mathrm{U}_{0} D$ using Two SMPs ${ }^{\mathrm{f}}$}

Figure 8 shows the cleaning radius as a function of $U_{0} D$ for the quad volute pump, standard slurry pump, and SMP. The cleaning radius plotted in Figure 8 is the minimum measured from the two pumps operated during the test. When a pump suspended the solids along one of the radial lines all the way to the center column or all the way to the tank wall, that radial line was not used to determine the cleaning radius. Some areas of the tank exhibited a larger cleaning radius than shown in Figure 8. The graph shows the cleaning radius to be a linear function of $\mathrm{U}_{0} \mathrm{D}$ and to be independent of the pump nozzle diameter (between 0.14 and 0.406 inches). A cleaning radius of $53-57$ inches is needed to ensure all of the MST particles are suspended with two pumps. ${ }^{\mathrm{g}}$

${ }^{\prime}$ Cleaning radii shown are for the SMP in riser B5.

${ }^{\mathrm{g}}$ Actual required cleaning radius depends on which side of the tank the last particles to be suspended are located. All of the MST particles could be suspended when the minimum measured cleaning radius is less than 57 inches. 


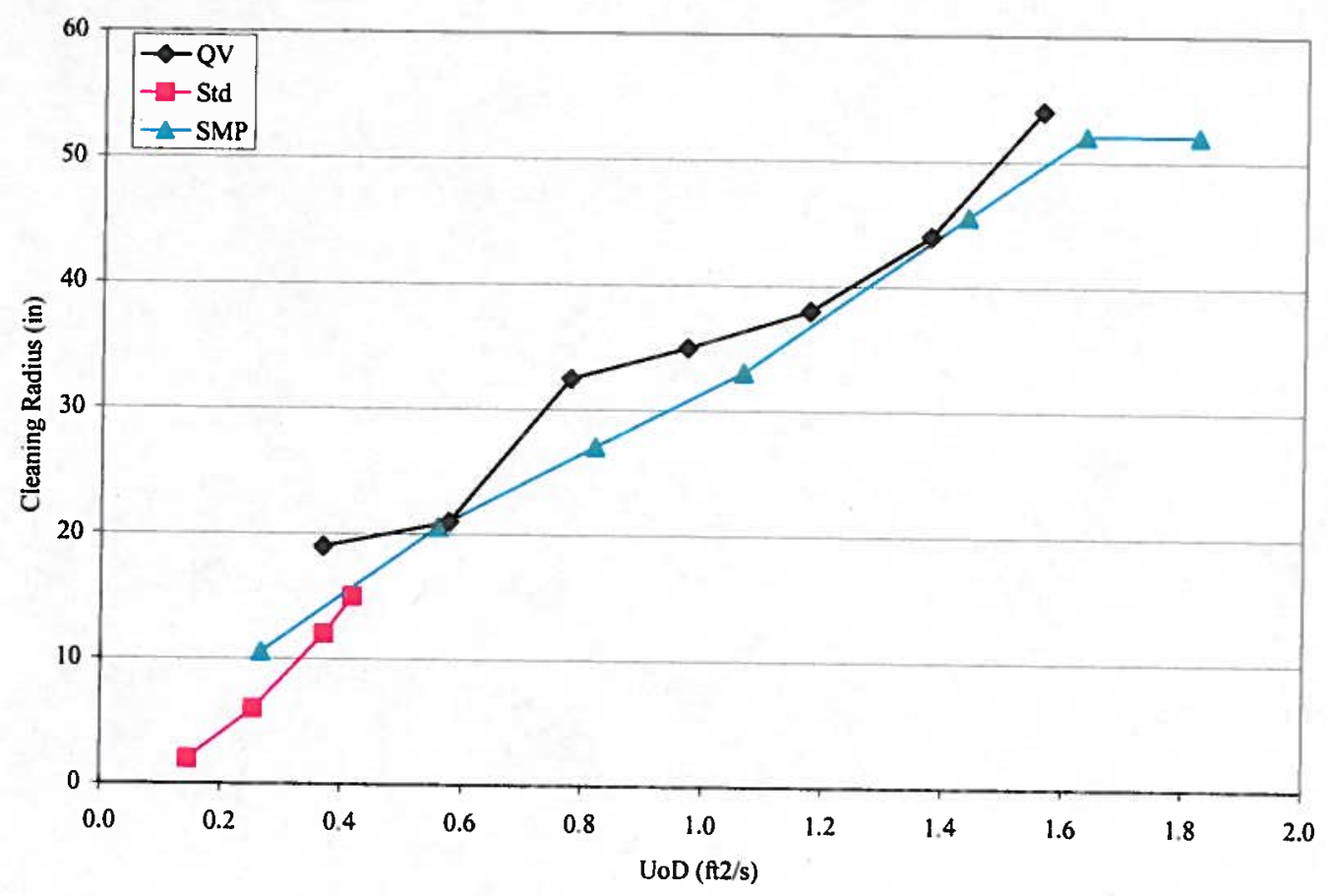

Figure 8. Cleaning Radius as a Function of $\mathrm{U}_{0} \mathrm{D}$

Table 2 shows the $U_{0} D$ needed to suspend all of the MST with each type of pump, as well as the predicted $\mathrm{U}_{0} \mathrm{D}$ needed to suspend the MST in a full-scale tank.

Table 2. Pump Parameters Needed to Suspend MST

$\begin{array}{llll}\text { Pump } & \text { 2 Standard } & \text { 2 Quad Volute } & \text { 2 SMP } \\ \mathrm{U}_{0} \mathrm{D}_{\text {pilot-scale }} & \text { Did not suspend } & 1.56 \mathrm{ft}^{2} / \mathrm{s} & 1.82 \mathrm{ft}^{2} / \mathrm{s} \\ \mathrm{U}_{0} \mathrm{D}_{\text {full-scale }}(\mathrm{n}=0) & \text { Will not suspend } & 16.9 \mathrm{ft}^{2} / \mathrm{s} & 19.7 \mathrm{ft}^{2} / \mathrm{s} \\ \mathrm{U}_{0} \mathrm{D}_{\text {full-scale }}(\mathrm{n}=1 / 9) & \text { Will not suspend } & 22.05 \mathrm{ft}^{2} / \mathrm{s} & 25.7 \mathrm{ft}^{2} / \mathrm{s} \\ \text { Max } \mathrm{U}_{0} \mathrm{D}_{\text {full-scale }} & 13.6 \mathrm{ft}^{2} / \mathrm{s} & 21.7 \mathrm{ft}^{2} / \mathrm{s} & 29.0 \mathrm{ft}^{2} / \mathrm{s}\end{array}$

The standard pump was not able to suspend all of the MST particles in the tank and had a maximum cleaning radius of $\sim 15$ inches. One reason for the small cleaning radius of this pump is the large resistances in the pump internals and nozzle. These large resistances result from decreasing the diameter of the pump internals and the pump nozzle. The maximum $U_{0} D$ achieved with this pump was $0.42 \mathrm{ft}^{2} / \mathrm{s}(37.5 \mathrm{ft} / \mathrm{s}$ nozzle discharge velocity). Even if the pilotscale standard pump would have been able to achieve the same nozzle discharge velocity as a full-scale standard pump (109 ft/s), the maximum $U_{0} D$ of the pilot-scale pump $\left(1.22 \mathrm{ft}^{2} / \mathrm{s}\right)$ would have been significantly less than the $\mathrm{U}_{0} \mathrm{D}$ needed by the quad volute and SMP pumps to suspend the MST $\left(1.56-1.82 \mathrm{ft}^{2} / \mathrm{s}\right)$. Two standard slurry pumps are not sufficient to suspend the MST in Tank $41 \mathrm{H}$ for the SCIX process. 
The quad volute pump was able to suspend all of the particles with a $\mathrm{U}_{0} \mathrm{D}$ of $1.56 \mathrm{ft}^{2} / \mathrm{s}(56.1 \mathrm{ft} / \mathrm{s}$ nozzle discharge velocity). Using the scaling described by equation [2], the required nozzle discharge velocity for two quad volute pumps to suspend the MST is $73 \mathrm{ft} / \mathrm{s}$, which exceeds the maximum discharge velocity of a quad volute pump ( $72 \mathrm{ft} / \mathrm{s})$.

The SMP was able to suspend all of the particles with a $\mathrm{U}_{0} \mathrm{D}$ of $1.82 \mathrm{ft}^{2} / \mathrm{s}(53.6 \mathrm{ft} / \mathrm{s}$ nozzle discharge velocity). Using the scaling described by equation [2], the required nozzle discharge velocity for two SMPs to suspend the MST is $70 \mathrm{ft} / \mathrm{s}$, which is $88 \%$ of the maximum discharge velocity of an SMP (79 ft/s).

According to Table 2, the quad volute pump was able to suspend all of the MST at a $U_{0} D$ of $1.56 \mathrm{ft}^{2} / \mathrm{s}$ versus a $\mathrm{U}_{0} \mathrm{D}$ of $1.82 \mathrm{ft}^{2} / \mathrm{s}$ for the SMP, a $17 \%$ difference. During these tests, the cleaning radius was measured at discrete values of $U_{0} D$ rather than continuously from 0 $1.82 \mathrm{ft}^{2} / \mathrm{s}$. The required $\mathrm{U}_{0} \mathrm{D}$ is between two measured values, with the larger value being shown in Table 2 and recommended for the SCIX mixer pumps. The actual required $U_{0} D$ for the SMP is between $1.63-1.82 \mathrm{ft}^{2} / \mathrm{s}$. The actual required $\mathrm{U}_{0} \mathrm{D}$ for the quad volute pump is between $1.38-1.56 \mathrm{ft}^{2} / \mathrm{s}$. At a $\mathrm{U}_{0} \mathrm{D}$ of $1.38 \mathrm{ft}^{2} / \mathrm{s}$ with the quad volute pumps, only two of the six radial lines showed complete suspension all the way to the center column or tank wall. However, at a $\mathrm{U}_{0} \mathrm{D}$ of $1.63 \mathrm{ft}^{2} / \mathrm{s}$ with the SMPs, complete suspension was observed along five of the six radial lines. Along the sixth radial line, MST suspension was observed to 55 inches along a 57 inch line. Therefore, a $\mathrm{U}_{0} \mathrm{D}$ of $1.63 \mathrm{ft}^{2} / \mathrm{s}$ was very close to suspending all of the MST particles.

\subsection{MST RESUSPENSION TEST WITH TWO PUMPS}

An MST resuspension test was conducted with SMP heads only based on results of the MST suspension tests described above. The two pump configuration was used for this test. The SMP was able to resuspend all of the particles that had settled for four weeks at nominal $45^{\circ} \mathrm{C}$ with a $\mathrm{U}_{0} \mathrm{D}$ of $2.40 \mathrm{ft}^{2} / \mathrm{s}\left(70.6 \mathrm{ft} / \mathrm{s}\right.$ nozzle discharge velocity). Table 3 shows the calculated $\mathrm{U}_{0} \mathrm{D}$ needed to resuspend the MST in a full-scale tank. Using the scaling described by equation [2], the required nozzle discharge velocity for two SMPs to resuspend the settled MST is $92 \mathrm{ft} / \mathrm{s}$, which exceeds the maximum discharge velocity of an SMP (79 ft/s). Because of this result, subsequent tests were performed with three pumps.

Table 3. Pump Parameters Needed to Resuspend MST after Settling for Four Weeks at 45 ${ }^{\circ} \mathrm{C}$

$\begin{array}{ll}\frac{\text { Pump }}{\mathrm{U}_{0} \mathrm{D}_{\text {pilot-scale }}} & \frac{2 \mathrm{SMP}}{2.40 \mathrm{ft}^{2} / \mathrm{s}} \\ \mathrm{U}_{0} \mathrm{D}_{\text {full-scale }}(\mathrm{n}=0) & 26.0 \mathrm{ft}^{2} / \mathrm{s} \\ \mathrm{U}_{0} \mathrm{D}_{\text {full-scale }}(\mathrm{n}=1 / 9) & 33.7 \mathrm{ft}^{2} / \mathrm{s} \\ \text { Max } \mathrm{U}_{0} \mathrm{D}_{\text {full-scale }} & 29.0 \mathrm{ft}^{2} / \mathrm{s}\end{array}$




\subsection{MST SUSPENSION TEST WITH THREE PUMPS}

Based on previous results, an MST suspension test was performed using three SMPs. Figure 9 shows sample cleaning radii measured during tests with three SMPs. A cleaning radius of 34 47 inches is needed to ensure all of the MST particles are suspended with three pumps. ${ }^{\text {h }}$

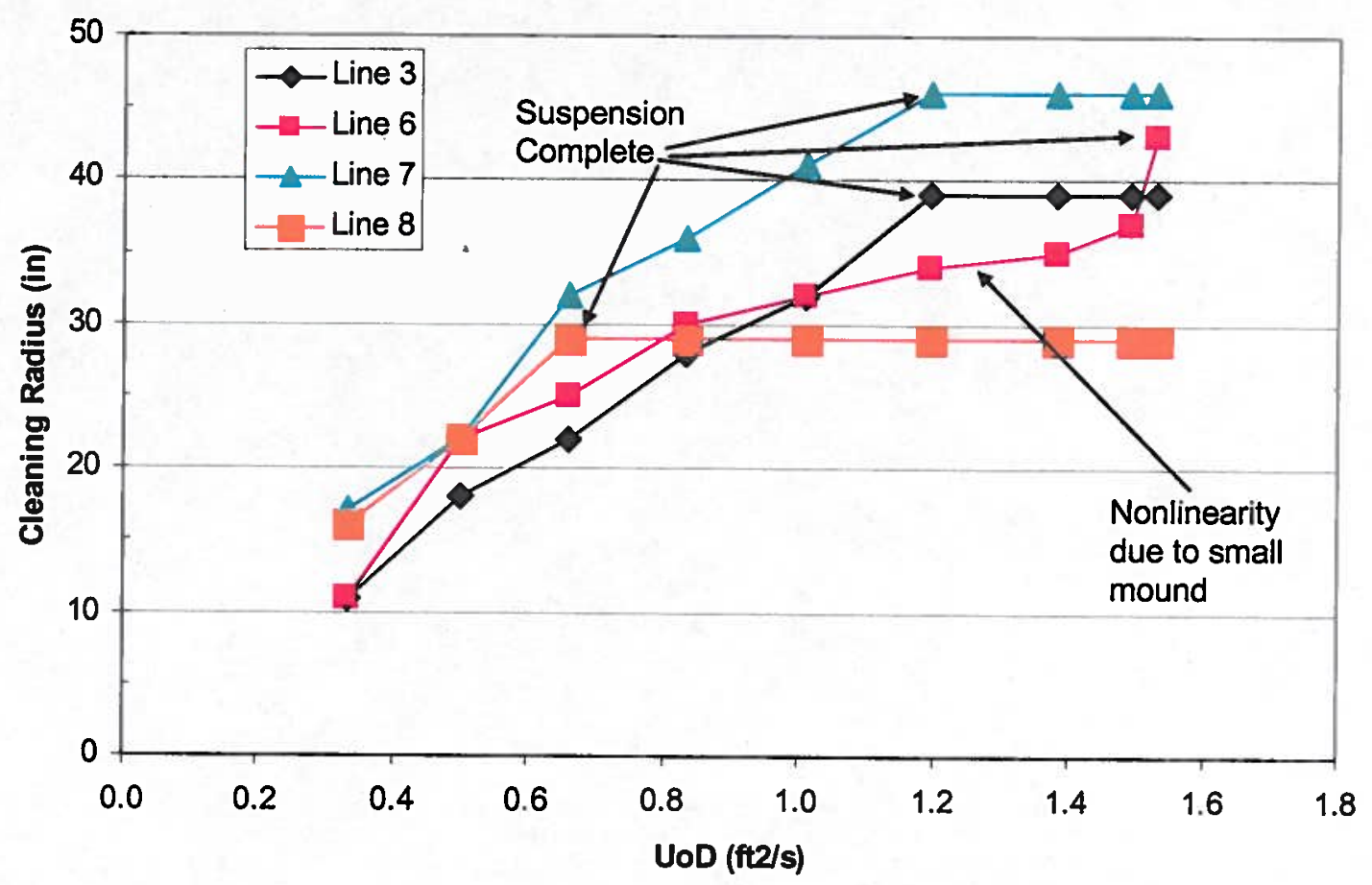

Figure 9. Cleaning Radius as a Function of $\mathrm{U}_{0} \mathrm{D}$ with Three SMPs during Initial Suspension Test

Table 4 shows the $U_{0} D$ needed to initially suspend MST with three SMPs in a full-scale tank. The SMP was able to suspend all of the particles with a $U_{0} D$ of $1.36 \mathrm{ft}^{2} / \mathrm{s}(40.1 \mathrm{ft} / \mathrm{s}$ nozzle discharge velocity). Using the scaling described by equation [2], the required nozzle discharge velocity for three SMP's to suspend the MST is $52 \mathrm{ft} / \mathrm{s}$, which is $66 \%$ of the maximum discharge velocity of an SMP (79 ft/s).

Table 4. Parameters Needed to Suspend MST

$\begin{array}{ll}\frac{\text { Pump }}{\mathrm{U}_{0} \mathrm{D}_{\text {pilot-scale }}} & \underline{3 \mathrm{SMP}} \\ \mathrm{U}_{0} \mathrm{D}_{\text {full-scale }}(\mathrm{n}=0) & 1.36 \mathrm{ft}^{2} / \mathrm{s} \\ \mathrm{U}_{0} \mathrm{D}_{\text {full-scale }}(\mathrm{n}=1 / 9) & 14.8 \mathrm{ft}^{2} / \mathrm{s} \\ \text { Max } \mathrm{U}_{0} \mathrm{D}_{\text {full-scale }} & 19.2 \mathrm{ft}^{2} / \mathrm{s} \\ & 29.0 \mathrm{ft}^{2} / \mathrm{s}\end{array}$

${ }^{\text {h }}$ Actual required cleaning radius depends on which area of the tank the last particles to be suspended are located. 


\subsection{MST RESUSPENSION TEST WITH THREE PUMPS}

Table 5 shows the $U_{0} D$ needed to resuspend MST with three SMPs in a full-scale tank. The table shows three SMPs will be able to resuspend MST that has settled for four weeks at nominal $45^{\circ} \mathrm{C}$, with $23 \%$ conservatism.

Table 5. Parameters Needed to Resuspend MST that Settled for Four Weeks at $45^{\circ} \mathrm{C}$
$\begin{array}{ll}\text { Pump } & \underline{3 \mathrm{SMP}} \\ \mathrm{U}_{0} \mathrm{D}_{\text {pilot-scale }} & 1.59 \mathrm{ft}^{2} / \mathrm{s} \\ \mathrm{U}_{0} \mathrm{D}_{\text {full-scale }}(\mathrm{n}=0) & 17.2 \mathrm{ft}^{2} / \mathrm{s} \\ \mathrm{U}_{0} \mathrm{D}_{\text {full-scale }}(\mathrm{n}=1 / 9) & 22.4 \mathrm{ft}^{2} / \mathrm{s} \\ \text { Max } \mathrm{U}_{0} \mathrm{D}_{\text {full-scale }} & 29.0 \mathrm{ft}^{2} / \mathrm{s}\end{array}$

Future tests will evaluate the ability of three SMPs to resuspend MST plus CST particles that have settled for four weeks at nominal $45^{\circ} \mathrm{C}$ and MST plus CST plus simulated sludge particles that have settled for four weeks at nominal $45^{\circ} \mathrm{C}$.

\subsection{CONCLUSIONS}

The conclusions from this analysis follow.

- Neither two standard slurry pumps nor two quad volute slurry pumps will provide sufficient power to initially suspend MST in an SRS waste tank.

- Two Submersible Mixer Pumps (SMPs) will provide sufficient power to initially suspend MST in an SRS waste tank. However, the testing shows the required pump discharge velocity is close to the maximum discharge velocity of the pump (within 12\%).

- Two SMPs will not provide sufficient power to resuspend MST that has settled in a waste tank at nominal $45^{\circ} \mathrm{C}$ for four weeks.

- Three SMPs will provide sufficient power to initially suspend MST in an SRS waste tank. The testing shows the required pump discharge velocity is $66 \%$ of the maximum discharge velocity of the pump.

- Three SMPs will provide sufficient power to resuspend MST that has settled in a waste tank at nominal $45^{\circ} \mathrm{C}$ for four weeks. The testing shows the required pump discharge velocity is $77 \%$ of the maximum discharge velocity of the pump.

\subsection{REFERENCES}

${ }^{1}$ K. M. L. Taylor-Pashow, M. R. Poirier, Z. Qureshi, F. F. Fondeur, T. B. Peters, D. T. Hobbs, and S. D. Fink, "Task Technical and Quality Assurance Plan for Testing to Support Modular Salt Processing Project - Monosodium Titanate Studies", SRNL-RP-2010-00686, Rev. 1.

${ }^{2}$ M. R. Poirier and Z. Qureshi, "Scaling Jet Mixing of MST-Containing Solids in the Small Column Ion Exchange Process", SRNL-STI-2010-00792. 